Efectos de la desigualdad de los sexos en la violencia en el hogar y en el embarazo indeseado en Colombia

En Colombia, la violencia conyugal contra la mujer es un grave problema de salud pública que tiene consecuencias físicas, reproductoras y de salud mental. En esa situación, es difícil que la mujer tome decisiones en torno a la reproducción, lo que a menudo redunda en embarazos indeseados (EI). Sobre esto hay pocos datos; la condición social de la mujer ha ido cambiando sustancialmente y ello se refleja en tasas de fecundidad que, de 6,8 al alborear el decenio de 1960, se redujeron a 2,6 en el año 2000. En ese año, $64 \%$ de las mujeres colombianas usaban algún tipo de anticonceptivo moderno. Se estima que las tasas de fecundidad actuales bajarían a 1,8 si reflejaran los verdaderos deseos de la mayoría. Se han explorado poco las consecuencias de vivir en un ambiente donde es común el riesgo o la amenaza de abuso por el compañero íntimo, pero merece investigarse cómo esa violencia influye en la capacidad de la mujer de controlar su fecundidad. Con ese objetivo, se realizó un análisis basado en teoría feminista sobre los datos recogidos en el año 2000 mediante la Encuesta colombiana de demografía y salud. Según esta teoría, los patrones de fecundidad son el resultado de normas legales y sociales que rigen las relaciones entre los sexos. Por otra parte, la fuerza de la influencia comunitaria hizo necesario el análisis multifactorial.

Mediante un muestreo probabilístico polietápico, se eligió a 3431 mujeres de la población encuestada que habían estado embarazadas en el transcurso de los cinco años anteriores. Se codificaron como maltratadas las que declararon haber sido empujadas, golpeadas, mordidas, pateadas o arrastradas, amenazadas con cuchillos, armas de fuego, estrangulación o quemadura, $\mathrm{u}$ obligadas a tener relaciones sexuales contra su voluntad. También se incluyeron variables socioeconómicas y demográficas; de autonomía social, sexual y doméstica; y del grado de control patriarcal ejercido por sus compañeros íntimos.

En promedio, las mujeres de la muestra tenían 28 años de edad y 2,3 niños cada una. La mayoría estaban casadas $(84,5 \%)$, mientras que aproximadamente $15 \%$ ya no lo estaban. Cerca de $50 \%$ habían cursado educación secundaria, 9\% educación más avanzada, $40 \%$ tenían educación primaria y solamente $3,36 \%$ dijeron no haber asistido a la escuela. Se registraron altas tasas de violencia a manos del compañero íntimo: $36,5 \%$ por maltrato físico y $8,5 \%$ por abuso sexual. Más de la mitad $(55,3 \%)$ habían tenido EI y 55\% usaban anticonceptivos en el momento de la encuesta. En cuanto a au- tonomía, $34,7 \%$ decidían los asuntos del hogar; menos de $30 \%$, el curso de su propia vida; y 73,9\%, su actividad sexual (cifra que debe interpretarse con cautela, pues se refiere a poder rehusar las relaciones sexuales en situaciones hipotéticas y no al comportamiento real).

La agregación de variables municipales no alteró los valores obtenidos sobre el abuso sexual o físico. El análisis de regresión logística multifactorial mostró que vivir bajo una fuerte influencia patriarcal casi cuadruplicaba la probabilidad de tener un EI, mientras que vivir en una municipalidad con altas tasas de violencia conyugal aumentaba 2,5 veces esa posibilidad. Además, las mujeres no maltratadas que vivían en municipalidades con altas tasas de violencia en el hogar corrían un riesgo significativo de EI. Las mujeres maltratadas que vivían en alguna municipalidad con altas tasas de autonomía femenina tenían más de cuatro veces las posibilidades de un EI. Los resultados muestran que vivir en una municipalidad caracterizable como patriarcal y donde es frecuente la violencia afecta al control reproductivo de una mujer aunque ella misma no sufra maltratos. De los resultados estratificados, la única variable significante en las mujeres maltratadas fue vivir en una municipalidad donde las mujeres estaban en libertad para tomar decisiones. Sin embargo, es posible que la toma de decisiones refleje el papel tradicional que desempeña la mujer en el hogar y no su propia autonomía. Se ha encontrado un aumento de violencia doméstica en zonas donde está mejorando la situación social de la mujer y el EI puede ser una forma de control para contrarrestarla.

Este estudio apoya la teoría feminista y el uso de métodos de análisis multifactorial como base para nuevas investigaciones sobre la salud reproductiva, si se agregan variables más sujetas a las fuerzas sociales que el EI. En los programas de salud reproductora, se recomienda obtener una participación mucho mayor de los hombres en la planificación familiar y prevención de la violencia para aumentar la seguridad de la mujer y en último término reducir la desigualdad de los sexos. (Payito CC, O'Campo P. Community level effects of gender inequality on intimate partner violence and unintended pregnancy in Colombia: testing the feminist perspective. Soc Sci Med 2005;60:2205-2216.)

\section{Comparación de dos sistemas de salud rurales descentralizados del noreste del Brasil}

A partir de la Declaración de Alma Ata en 1978, se esperaba que los sistemas de salud llegaran a ponderar tanto la promoción de la salud como la 